\title{
As visões do conhecimento matemático e as repercussões na prática pedagógica
}

\author{
Samira Zaidan ${ }^{1}$ \\ Sandra de Lacerda Cardoso ${ }^{2}$
}

\section{Resumo}

Neste trabalho, temos por objetivo explorar questões relativas às repercussões na prática pedagógica, a partir da visão do docente, sobre a disciplina por ele ministrada. Surge como parte dos resultados gerados por uma pesquisa, de cunho qualitativo (CARDOSO, 2013), sobre repercussões na prática pedagógica que professores egressos atribuem a uma especialização em Educação Matemática. O curso analisado está em uma das áreas de concentração do Programa de Pós-Graduação Lato Sensu em Docência na Educação Básica (Laseb), uma parceria entre a Faculdade de Educação da UFMG e a Secretaria Municipal de Educação de Belo Horizonte. O material empírico constou da consulta a documentos do Laseb e questionário/entrevista com treze professores egressos. Neste artigo, exploraremos algumas relações que podem ser inferidas, quais sejam: entre uma visão mais formal da Matemática e, também, da relação mais formal entre professor-aluno, em contrapartida a uma visão mais flexível da Matemática e uma relação mais interativa com os alunos.

Palavras-Chave: formação docente; Laseb; educação matemática.

1 Doutora em Educação pela UFMG. Professora da Faculdade de Educação da UFMG, Brasil. samirazai@hotmail.com

2 Mestre em Educação pela Universidade Federal de Minas Gerais (UFMG). Professora do Instituto Federal de Educação, Ciência e Tecnologia do Triângulo Mineiro (IFTM), campus Patrocínio (MG), Brasil. 


\title{
A discipline's view and its repercussions on pedagogical practice (the case of Mathematics teaching)
}

\begin{abstract}
The present work aims at exploring questions related to the repercussion on pedagogical practice, from the teacher's view on the discipline taught by him. This study arises from the results produced by a qualitative research (CARDOSO, 2013), about the repercussions on the pedagogical practice that teachers attribute to an specialization in Mathematical Education. The course analyzed consists on one of the concentration areas of the Programa de Pós-Graduação Lato Sensu em Docência na Educação Básica [Lato Sensu Pos-graduation Program on Teaching in Fundamental Education] - Laseb, a partnership between Faculdade de Educação [Education Faculty] of Universidade Federal de Minas Gerais [Federal University of Minas Gerais] - UFMG and Secretaria Municipal de Educação [Municipal Education Secretary] SMED/BH. The empirical material consisted of reviews of Laseb's documents and questionnary/interview with thirteeen egress teachers. In this article, we will explore some relationship that can be inferred, namely: between a more formal mathematical view, and also, of the more formal relationship between teacherstudent, in contrast to a more flexible view of mathematics and a more dialogical relationship with the students.
\end{abstract}

Keywords: teacher education; Laseb; mathematics education.

\section{Introdução}

Pretendemos apresentar neste trabalho questões que surgiram a partir de resultados de uma pesquisa que mostra existir relações entre "como" o docente vê o conhecimento disciplinar e o seu "modo de ensinar", destacando a relação com seus alunos.

A pesquisa de Cardoso (2013) com professores graduados em Matemática, egressos da Especialização Laseb-FaE/UFMG, analisou as 
repercussões desse curso na prática pedagógica por meio da visão do docente. Quando da leitura dos textos produzidos a partir das entrevistas sobre como os docentes viam as repercussões do curso de especialização em suas próprias práticas, pôde-se constatar que todos se referiam a novas relações que passaram a estabelecer com os seus alunos.

Tal situação se mostrou intrigante e desafiadora. É necessário explicitar que o Curso de Especialização Laseb se desenvolveu durante dezoito meses, tendo como foco novas abordagens para o ensino de Matemática, com a) seminários e três disciplinas com estudos de temas gerais da educação; b) oficinas, como momento de vivenciar e aprender praticando, com enfoque em redação-arte-tecnologias; c) sete disciplinas voltadas para abordagens e metodologias de ensino dos fundamentos da Matemática no Ensino Fundamental; e, finalmente, d) uma disciplina de análise da experiência docente e elaboração de um "Projeto de Ensino" desenvolvido, total ou parcialmente, durante o curso. Por que, então, entre os muitos elementos presentes nas entrevistas, de maneira, às vezes, bem explícita e noutras, nas entrelinhas, todos os egressos se referiam a uma relação mais próxima com seus alunos a partir da vivência do curso?

Apresentamos este artigo como um estudo que extrapola, na medida em que iremos fazer análises e indicações que não foram aprofundadas na própria pesquisa indicada, nem tratada de um modo específico com os docentes entrevistados. Acreditamos, contudo, que as indicações são importantes e que, as considerações aqui feitas, podem colaborar tanto para melhor compreensão dos processos formativos em serviço quanto para a ampliação dos conhecimentos teóricos na área da educação matemática.

A questão norteadora da pesquisa foi: quais as possíveis repercussões do Laseb na prática pedagógica de professores graduados em Matemática, egressos da área de concentração em Educação Matemática? A partir dessa questão geradora, outras também se fizeram presentes, a saber: quais eram as expectativas dos professores egressos com relação ao Laseb?; quais foram os limites enfrentados por eles durante e após essa formação continuada?; se os professores egressos perceberam uma ampliação, aprofundamento e/ou melhora do seu desenvolvimento 
profissional e/ ou pessoal; se essa formação continuada contribuiu para a reflexão da prática pedagógica dos professores egressos e de que forma isso ocorreu.

O Laseb/Ed. Mat. constituía, a cada edição, uma turma de 40 professores atuantes nos nove anos do Ensino Fundamental, oportunizando, especialmente, o estudo e o debate do ensino dos fundamentos da Matemática, ancorado nas teorias da educação matemática (D'AMBROSIO, 1999; FIORENTINI, 1994; DAVID, 2001; entre outros). Pôde-se constatar, na pesquisa de Cardoso (2013), a importância da composição heterogênea das turmas tanto por professores que ensinam Matemática nos anos iniciais quanto por professores graduados em Matemática, pois um pôde compreender e se articular melhor com o outro. Fizemos a opção pelo termo "repercussões" pela possibilidade de compreensão de múltiplos aspectos de uma formação continuada que o termo poderia nos fornecer ao darmos voz aos professores os quais é quem iriam dar o "tom" do referido estudo.

\section{Explicitando alguns conceitos}

Para melhor entendimento da análise que aqui faremos, buscamos uma compreensão mais clara sobre a "formação docente" continuada, pois várias são as terminologias utilizadas ao longo dos últimos anos. Entre essas, encontramos: reciclagem, treinamento, aperfeiçoamento, capacitação, educação permanente, formação continuada e educação continuada (MARIN, 1995). Conforme pontua essa autora, o termo "reciclagem" esteve em evidência na década de 1980 e envolvia profissionais de diferentes áreas, inclusive, os da educação, destacando o fato de esse termo ser bastante comprometedor quando estamos lidando com pessoas, uma vez que, para haver reciclagem, há necessidade de alterações radicais no objeto ou material que está sendo manipulado, o que não é compatível com a ideia de atualização pedagógica.

Outro termo que é utilizado na área de educação é "treinamento". Marin (1995) ressalta que é possível e até mesmo necessário em algumas situações trabalhar com treinamentos, mas em se tratando de 
profissionais da Educação, é um equívoco conceber esse formato, pois, para atingir pessoas, é preciso mais que meras finalidades mecânicas desvinculadas de manifestações dos sujeitos envolvidos no processo. Para o verbete "aperfeiçoamento", Ferreira (1986, p. 141) cita "tornar perfeito ou mais perfeito; acabar com perfeição; concluir com esmero; perfazer ou completar (o que estava incompleto); adquirir maior grau de instrução ou aptidão; emendar os próprios defeitos; corrigir-se, emendarse". Marin (1995) coloca que perfeição no processo educativo seria não ter falhas, mas salienta que na Educação há que se conviver com acertos e fracassos, uma vez que são muitos os fatores que intervêm na área. Marin (1995, p. 16) comenta que é negar a própria essência da Educação, "pensar no processo educativo como um conjunto de ações capaz de completar alguém, de torná-lo perfeito, de concluí-lo". É possível, assim, perceber que o termo "aperfeiçoamento" não explicita adequadamente as pretensões e demandas relativas à formação docente.

Continuando a dialogar com a autora, chegamos ao termo “capacitação". Segundo Ferreira (1986, p. 340), capacitar significa "tornar capaz; habilitar e também convencer, persuadir". Nesse sentido, a autora destaca que o termo capacitação, quando se refere a "tornar capaz" ou "habilitar", pode ser coerente com a ideia de formação continuada, já que é necessário que as pessoas, para melhor desempenharem as suas funções, sejam capacitadas. Mas o mesmo não ocorre quando capacitar significa "convencer" ou "persuadir", pois é por meio do uso da razão, e não do convencimento ou persuasão, que os profissionais da Educação deverão conhecer, analisar, criticar e aceitar ideias, abolindo qualquer forma de imposição de pensamentos, métodos ou comportamentos como axiomas a serem aceitos sem nenhum tipo de contestação.

Finalmente, Marin (1995) também nos apresenta três conjuntos de termos que podem ser colocados num mesmo bloco devido à similaridade entre eles no entendimento de ser o conhecimento o centro da formação de professores. Esses termos são a "educação permanente", "a formação continuada" e a "educação continuada". Segundo a autora, há uma multiplicidade de termos para se referir à formação de professores, mas diz preferir a terminologia educação continuada por achar que essa faça abordagens mais amplas 
dependendo da perspectiva a ser focalizada no processo educativo. Em nosso entendimento, os três termos citados são bem satisfatórios para se referir a processos de formação dos profissionais da educação.

Ainda com relação à apropriação da terminologia em questão, deparamo-nos com Marcelo Garcia (2009). Ele prefere adotar o termo "desenvolvimento profissional docente" em vez de formação inicial e continuada de professores. $\mathrm{O}$ autor justifica essa preferência ao colocar que o termo se adéqua mais claramente à concepção do profissional que lida com o ensino, além de o conceito "desenvolvimento" sugerir evolução e continuidade que, segundo ele, rompe com a tradicional justaposição entre formação inicial e formação continuada. O processo do desenvolvimento profissional é algo mais complexo por envolver uma multiplicidade de fatores, pois está sujeito a influências e pressões de vários tipos de instâncias.

Também encontramos a terminologia "formação em serviço". Placco (2010), respaldada em estudos de outros autores, faz uma análise sobre a "formação em serviço", argumentando que se trata de um processo bastante complexo por envolver apropriação de saberes e conhecimentos que estão imbricados com o exercício profissional docente. Segundo a autora, toma-se a escola como lócus privilegiado para a formação, mas para que esse processo de formação aconteça, ele precisa atender certas condições, como estar ligado ao projeto político pedagógico da escola; ser planejado e implementado de forma coletiva pelo corpo docente da escola; prever espaços e tempos para que as formações possibilitem a participação de todos os professores, além de oportunizar reflexões, valorização da experiência prévia dos seus sujeitos e trocas de experiências. Concordamos com as colocações de Placco (2010) sobre "formação em serviço", mas entendemos que essa expressão pode ser ampliada para atender as formações nas quais se encontram professores que são liberados das atividades que, por ventura, venham a acontecer em suas respectivas escolas ou fora de seus espaços, para frequentar alguma atividade ou curso para o qual se inscreveram, com autorização/ respaldo da sua instituição de ensino. Assim sendo, entendemos que, apesar de a formação ocorrer dentro ou fora da escola, ela se volta 
para a prática pedagógica do professor, portanto, também se configura uma "formação em serviço", e vem somar às outras formações que os professores possam ter acesso em diferentes espaços, inclusive o próprio espaço escolar.

Essa reflexão que fizemos, quanto aos termos que são utilizados quando se faz referência à formação dos profissionais da Educação que já concluíram a graduação, foi muito importante para situarmos a nossa pesquisa nessa vasta terminologia.

No nosso trabalho, utilizamos as terminologias "formação em serviço", "formação continuada" e/ou "educação continuada", sendo que os dois últimos termos são utilizados em documentos oficiais, como a LDB n ${ }^{\circ} 9.394 / 96^{3}$ e a Portaria $n^{0} 1.403^{4}$, de 9 de junho de 2003, para se referir aos profissionais da Educação que vivenciam uma formação que toma como referência as questões da prática. Também nos interessam esses termos por serem mais simples e expressivos das ações e processos formativos vividos pelos docentes.

Sobre a terminologia "prática pedagógica", comungamos com Caldeira e Zaidan (2010), ao descreverem que a prática se constrói no dia a dia da ação docente na escola. As autoras pontuam que na prática pedagógica estão presentes, concomitantemente, ações práticas mecânicas e repetitivas necessárias ao trabalho do professor, assim como as ações práticas criativas diante de situações particulares que ocorrem, as quais abrem possibilidades para que esse profissional possa refletir sobre a sua prática por meio de outras perspectivas e construir alternativas. Segundo as autoras,

A Prática Pedagógica é entendida como uma prática social complexa que acontece em diferentes espaço/tempos da escola, no cotidiano de professores e alunos nela envolvidos e, de modo especial, na sala de aula, mediada pela interação professoraluno-conhecimento. Nela estão imbricados, simultaneamente, elementos particulares e gerais. Os aspectos particulares dizem respeito: ao docente - sua experiência, sua corporeidade, sua

3 LDB n 9.394/96. Disponível em: <http://www.planalto.gov.br/ccivil_03/leis/L9394.htm>. Acesso em: 17 abr. 2012.

4 Portaria $\mathrm{n}^{\circ} 1.403$, de 9 de junho de 2003, institui o Sistema Nacional de Certificação e Formação Continuada de Professores. Disponível em: <http://www.educacional.com.br/legislacao/diario. pdf >. Acesso em: 17 abr. 2012. 
formação, condições de trabalho e escolhas profissionais; aos demais profissionais da escola suas experiências e formação e, também, suas ações segundo o posto profissional que ocupam; ao discente - sua idade, corporeidade e sua condição sociocultural; ao currículo; ao projeto político-pedagógico da escola; ao espaço escolar suas condições materiais e organização; à comunidade em que a escola se insere e às condições locais. (CALDEIRA; ZAIDAN, 2010, n.p.)

Assim sendo, a prática pedagógica envolve diferentes sujeitos que trazem consigo histórias/memórias e que fazem parte de um determinado contexto, que, por sua vez, está envolvido por condições muito peculiares. A prática pedagógica, nessa visão, configura as ações desenvolvidas e vivenciadas na escola. Foi a partir dessa perspectiva de prática pedagógica que enveredamos com o nosso estudo, mas conscientes da necessidade de, durante todo o percurso da pesquisa, nos debruçarmos em desvelar os múltiplos elementos que compunham esse conceito.

Com relação à Matemática, D'Ambrosio (1993) coloca que é a única disciplina que atingiu um caráter de universalidade no que concerne aos sistemas educacionais. Pontua que "não encontraremos, no cotidiano de todos os povos e de todas as culturas, atividades que não envolvam alguma forma de Matemática." (p. 8-9). Ao trazermos neste estudo o termo Matemática, estamos nos referindo a uma ciência da ordem, que se edifica por uma estrutura bem rigorosa e que envolve um conjunto de elementos, a saber: convenções, definições, conceitos, teoremas (demonstrações), axiomas (postulados). Nesse sentido, remetemo-nos a Moreira e David (2007) que apresentam um entendimento de Matemática Científica ou Matemática Acadêmica. Segundo os autores, essas duas expressões são "sinônimos que se referem à Matemática como um corpo científico de conhecimentos, segundo a produzem e a percebem os matemáticos profissionais" (p. 20).

No que concerne à Educação Matemática, recorremos a Araújo $^{5}$, que nos traz um conceito muito expressivo para essa terminologia:

A Educação Matemática é um campo do conhecimento que se dedica a estudar questões relativas ao ensino/aprendizagem de matemática. É um campo interdisciplinar que faz uso de teorias de 
outros campos teóricos, como a sociologia, a psicologia, a filosofia, etc., para a construção de seu conhecimento, além de construir suas próprias teorias. A Educação Matemática não se restringe a apenas estudar meios de fazer alunos alcançarem um conhecimento previamente estabelecido, mas também problematiza e reflete sobre o próprio conhecimento matemático. (ARAUJO, 2012, n.p.)

Acreditamos que a apresentação das terminologias utilizadas neste estudo poderá auxiliar o leitor a compreender as análises feitas a partir das colocações dos nossos sujeitos de pesquisa.

\section{A pesquisa}

Uma vez constituído o grupo de docentes egressos do Laseb/Ed. Mat., perguntamos sobre a formação continuada e exploramos com cada um sobre as repercussões que percebiam em suas práticas após a vivência do curso. Cada entrevista resultou em um texto que foi devolvido ao respectivo entrevistado para que pudesse opinar sobre a transcrição feita. Quando do retorno, os textos foram fontes dos estudos realizados para desvelar a resposta à pergunta inicial. A pesquisa indica uma regularidade nas falas dos professores egressos, no que diz respeito a colocações de forma reiterada sobre questões ligadas aos seus modos de ver e fazer Matemática em sua prática de ensino. Muitos falaram que puderam ter contato com metodologias diferentes, outros expuseram ter ampliado seus conhecimentos da própria Matemática e todos destacaram as novas relações que diziam estabelecer no contexto escolar, especialmente com os seus alunos.

Vejamos, pois, a opinião do professor Jair:

Eu achava que [o Curso] ia ser um monte de conteúdo, que eu tinha que revisar uma série de coisas. E ai não, a surpresa foi essa! Como eu vou chegar no meu aluno com esse conteúdo? A álgebra, como eu vou trabalhar? Qual o caminho que eu tenho para desenvolver certos conteúdos?

Foi uma surpresa boa. Porque [o Curso] veio ao encontro daquilo que eu buscava, que era entender o meu aluno. E o aluno de hojeé bem diferente do aluno de 20 anos atrás. A Educação Matemática, eu já buscava isso, e lá eu tive a certeza que a saída para a realidade hoje é essa. Aquela Matemática fechada, formal, ela cabe para quem for matemático. Mas 
os nossos alunos aqui, não precisam ter essa visão rigorosa, formal, determinada. (Professor Jair, grifos nossos)

Da mesma forma, o professor João nos relatou que, a partir do Laseb, a sua prática transformou (palavra utilizada por ele), mas que a princípio ele mesmo não havia percebido isso. Nesse sentido, contou sobre uma observação feita pela coordenadora da escola particular na qual estava atuando.

A Coordenadora pedagógica da escola particular, ela até falou -é incrível como você mudou. [...] Falei - Engraçado, que eu não percebo. Mas ela disse: Mas mudou sim. Sempre tive uma relação excelente com o aluno. Mas o que ela fala é que até os exercícios estão diferentes. Às vezes eu sinto que aqui na escola o pessoal passa e dá uma olhada mesmo, escola particular volta e meia o coordenador dá uma olhadinha como é que tá. A gente nem vê, às vezes. Então ela fala - eu vejo os exemplos que você dá, as histórias que você conta, tem uma coisa diferente. Ela também não soube explicar. Mas a gente começa a preocupar com alguns detalhes que a gente não preocupava antes. (Professor João, grifos nossos)

Este professor nos disse que, naquele momento, estava atuando na escola particular como professor, pois não queria se distanciar da sala de aula, mas também como coordenador. "Porque assim que eu terminei o curso, a escola me convidou para ser coordenador - então já é um resultado...", disse sorrindo para a pesquisadora. Continuou fazendo as suas colocações, dessa vez pontuando a importância do planejamento, de avançar e retomar o ensino dos conteúdos matemáticos, focando sua atenção nos alunos:

[...] embora não seja uma coisa que a gente perceba, engraçado, você não percebe...é que algumas coisas eu comecei a direcionar mais. Quando eu ia dividir tal tempo, aí eu já tinha preocupação-Quais as habilidades que o aluno precisa ter? Que tipo de pensamento, de raciocínio ele precisa ter para alcançar isso aqui? - aí eu comecei a procurar atividades..., aí é o que eu acho que mais o Curso, como é que eu posso dizer, me instrumentalizou, me acrescentou, foi isso, de estar atento.

É aí então que você vê que tem que discutir com mais detalhes, você tem que voltar. Isso aí é uma coisa que cada vez está mais clara pra mim. O aluno nunca está pronto em Matemática. Você não pode - ah isso é pré-requisito para $6^{\circ}$ ano e eu não tenho que trabalhar no $8^{o}$. Você tem que retomar. [...] Você planta uma sementinha e ela fica lá. Você tem que regar sempre. (Professor João, grifos nossos) 
A formação é um momento para o profissional poder refletir. Schön (1992, p. 85), citando Raymond Hainer, coloca: "Só se pode ter uma nova perspectiva sobre alguma coisa após nos termos afastado dela". A formação continuada é uma oportunidade de o professor olhar a sua escola, os seus alunos, os conteúdos que ensina e a sua prática, ampliando o seu ponto de vista.

Os professores também relataram como contribuição do Curso de Especialização o fato de terem contato com a Matemática sob "outra perspectiva", favorecendo que eles pudessem se apropriar do que vem a ser a Educação Matemática. O professor Bruno, por exemplo, relatou que

[...] aquele conhecimento teóóórico, vamos dizer assim, bem de ICEx ${ }^{6}$ / UFMG, muito bom como crescimento pessoal, acho que isso éfundamental, mas eu não conseguia aproximar muito desses meus alunos de Prefeitura. Às vezes eu observava o colega fazendo um trabalho um pouco diferente, $e$ a gente às vezes meio que preconceituoso - ah, mas isso de repente está baixando muito o nível da Matemática - enão épor aí. Lá [referindo-se ao Laseb] eu acho que eu perdi... talvez a palavra preconceito seja pesada, mas na hora que eu observei professores [referindo-se aos formadores] que dão um outro tipo de enfoque para aquela Matemática do ICEx, e como me aproximar daqueles meninos... sabe, daquelas meninas, eu acho que [...] alguma coisa mudou, uma barreira, mudou. Tipo assim... olha, isso não é baixar o nível não. O pessoal está estudando, está pesquisando, está vendo que realmente você tem que mudar o enfoque. A questão daquela Matemática teoria, teoria, teoria... Eu acho que isso também me ajudou bastante. (Professor Bruno, grifos nossos)

Ao colocar "ICEx" e "FaE", referindo-se ao Instituto que focaliza a "Matemática" e à Faculdade que focaliza a "educação matemática", respectivamente, o professor egresso aponta a contradição e o debate que existe nos dias de hoje no campo da formação docente como um todo e do professor de Matemática em particular. Estávamos diante de um relato que trazia questões sobre a maneira como a Matemática tinha sido abordada à época em que o professor havia cursado a licenciatura em Matemática e o seu sentimento com relação a esse fato. Da mesma forma, outros professores também comentaram sobre a questão de não estarem "ensinando" nas suas salas de aula os conhecimentos

6 ICEx - Instituto de Ciências Exatas - UFMG/BH, que oferece os cursos de licenciatura e bacharelado em Matemática, assim como pós-graduação lato sensu e stricto sensu. 
matemáticos apreendidos durante a graduação, que foram adquiridos a partir de uma abordagem formal da Matemática.

Os professores entrevistados, todos graduados em Matemática, inicialmente se apresentaram como sendo conhecedores do conteúdo matemático, mas ao mesmo tempo, relataram perceber que só esse conhecimento não se mostrava suficiente para lidar com o processo de ensino e aprendizagem no dia a dia das suas salas de aula. Explicitaram que viviam conflitos na sua ação docente porque não conseguiam ensinar como esperavam, apesar de muitas tentativas, sendo esse, inclusive, um dos principais motivos de procura pela especialização. Colocaram a enorme necessidade de resgatar os conceitos básicos da Matemática e, principalmente, de aprender como ensiná-los para os seus alunos de $3^{\circ}$ ciclo do Ensino Fundamental. Queriam novas formas de mostrar a Matemática para os seus alunos. Por esses motivos, entendemos que o estudo dos conceitos da Matemática na perspectiva do ensino, como concebe a educação matemática e possibilitada pelo curso, lhes caíram muito bem, pois mostraram novas possibilidades para a prática pedagógica, como que abrindo caminhos.

Os entrevistados também fizeram relatos sobre algumas disciplinas cursadas no Laseb e como os conteúdos foram ministrados pelos formadores, especialmente rompendo com a perspectiva do ensino por pré-requisitos, flexibilizando as abordagens dos conteúdos fundamentais da Matemática (por exemplo, registrando o cálculo mental e variando os registros dos algoritmos até que o aluno pudesse compreender o registro formal). A professora Isa fez o seguinte comentário sobre a disciplina Fundamentos do ensino de Matemática IV - geometria plana e espacial, estudada no Curso de Especialização:

[...] aquela ideia de você trabalhar a partir dos sólidos para depois dar a figura plana... você parte atualmente do sólido, do concreto para atingir o estudo da geometria dentro da figura plana, eu aprendi lá, que eu poderia fazer isso sem atrapalhar o andamento do conteúdo. Então hoje, por exemplo, se eu vou falar de quadrado, eu apresento primeiro um cubo como sendo um sólido e a partir dele nós vamos destrinchando até chegar ao quadrado e a partir daí, estudamos os elementos do quadrado. Foi um negócio interessante que eu achei que nós aprendemos lá. (Professora Isa) 
Já o professor Bruno relatou que não usava muito o material concreto em suas aulas, mas que, após se apropriar dessa nova maneira de ensinar, com a abordagem dos sólidos utilizando diversos recursos, incorporou essa nova possibilidade às suas aulas. "O jogo de sombras e trabalhar com palitos... acho que, no caso dos sólidos geométricos, isso é fora de série. Você passar a construir com eles [os alunos] alguns sólidos; acho que isso aí também foi coisa que eu aprendi lá." (Professor Bruno).

Estudos, como os de Lorenzato (1995), Pavanello (1993), entre outros autores, chamam a atenção para os possíveis fatores que resultam num descaso com o ensino de Geometria. Uma das principais causas se deve ao fato de o professor não deter conhecimentos geométricos suficientes para realizar a sua prática, fazendo com que seu aluno, inevitavelmente, tenha uma aprendizagem comprometida.

A professora Flora relatou ter gostado muito da parte de Estatística trabalhada no curso e que isso foi um dos fatores que a motivou a fazer outro vestibular, dessa vez nessa área, sendo que já era aluna do curso de Estatística da UFMG quando da entrevista que nos concedeu. A referência que fez diz respeito à disciplina Fundamentos do ensino de Matemática $V$ - tratamento da informação estatística e probabilidade. Ela fez o seguinte relato:

A gente trabalha com o início de probabilidade quando a gente dá aula para a sétima série, mas a gente não se diverte tanto como, por exemplo, com o Nepso, com essas questões que ela [referindo-se à formadora] trouxe e, que são questões que envolvem análise, pesquisa, gráfico... Os alunos gostam e é uma área extremamente atrativa. Então, a professora realmente foi uma fonte inspiradora porque ela ampliou a minha visão dessa questão da estatística relacionada à educação. (Professora Flora).

Dos professores pesquisados, dois apontaram opiniões mais críticas. Um deles relatou que o Laseb the proporcionou um crescimento pessoal, mas criticou a pouca instrumentalização do docente, uma vez que gostaria de "mais ferramentas" para o ensino, "técnicas de ensino, técnicas de como eu abordo um tema com o aluno". Ambos os docentes salientaram o fato de o Laseb tratar a Matemática de modo bem diferente daquela que haviam estudado, tendo em vista os seus tempos de regentes e também de vida sendo, dessa forma, considerados dificultadores de 
mudança de suas posturas. Ou seja, esses docentes explicitaram não aceitar essa "novidade".

\section{Um ensino marcado pela lógica da educação bancária}

Como vimos na seção anterior, os docentes pesquisados, egressos do Laseb/Ed.Mat., tomaram contato com a Matemática do ponto de vista do ensino, no foco da Educação Matemática, o que mostrou um caminho muitas vezes diferente do esperado por eles quando se inscreveram no curso. Perguntamos-nos: será que os egressos do Laseb graduados em Matemática tinham expectativa de uma formação como um "treinamento" nos conteúdos matemáticos? O que esperavam?

Certo é que os docentes egressos se referiam sempre à mudança da relação com os alunos como a principal repercussão do Laseb em suas práticas. Não tivemos a oportunidade, pelo tempo de realização da pesquisa, de observar e participar das suas aulas, o que poderia nos dar elementos mais consistentes de análise. Contudo, considerando os relatos dos próprios docentes, vamos apresentar alguns elementos teóricos que podem auxiliar no melhor entendimento das possíveis relações entre a visão do docente sobre o conhecimento matemático e a relação que ele estabelece na sua sala de aula.

Acreditamos poder inferir que uma visão mais flexível sobre o conhecimento da disciplina Matemática pode indicar relações mais interativas e dialogais de ensino e que, por consequência, sejam mais harmoniosas na sala de aula.

O ensino de Matemática conviveu e convive com práticas bastante diferenciadas e, obviamente, em contextos bastante variados também. Contudo, podemos dizer que há um "estilo" que, historicamente, é bastante comum no ensino de Matemática, modelo esse proveniente de uma visão tradicional de ensino. Vejamos alguns estudos.

D’Ambrosio (1989, p. 15) explica que "a típica aula de matemática [...] ainda é uma aula expositiva, em que o professor passa no quadro negro aquilo que ele julga importante. $\mathrm{O}$ aluno (...) copia da lousa para o seu caderno e em seguida procura fazer exercícios de aplicação [...]". 
Barth (1993) também destaca que, tradicionalmente, saber ensinar é saber expor conteúdos bem estruturados pelo professor.

O modo de "ver e conceber" o ensino de matemática tem certamente como base uma visão de educação, uma visão de matemática e de educação matemática. Fiorentini (1994) apresenta a ideia de que

[...] por trás de cada modo de ensinar, esconde-se uma particular concepção de aprendizagem, de ensino e de educação. O modo de ensinar depende também da concepção que o professor tem do saber matemático, das finalidades que atribui ao ensino de matemática, da forma como concebe a relação professor-aluno e, além disso, da visão que tem de mundo, de sociedade e de homem. (FIORENTINI, 1994, p. 38)

No Brasil, os anos setenta e oitenta são marcados pela visão tecnicista de educação e no ensino de Matemática. Segundo Fiorentini (1994, p.48-49, grifo nosso), “[...] do confronto entre o MMM [Movimento da Matemática Moderna] e a pedagogia tecnicista surge a combinação: tecnicismo-formalista."

[...] A abordagem é tecnicista porque enfatiza o emprego de técnicas de ensino [...] cujos conteúdos aparecem dispostos em passos sequenciais, atendendo aos objetivos instrucionais previamente apresentados que priorizam o treino de habilidades técnicas através da realização de uma série de exercícios do tipo: "resolva os exercícios abaixo, seguindo o seguinte modelo [...]" É formalista enquanto enfatiza a matemática pela matemática, suas fórmulas, seus aspectos estruturais, suas definições (iniciando geralmente por elas) [...] porque se preocupa exageradamente com a linguagem, com o uso correto dos símbolos, com a precisão, com o rigor, sem dar atenção aos processos que os produzem; porque enfatiza o lógico sobre o psicológico, o formal sobre o social, o sistemático-estruturado sobre o histórico; porque trata a matemática como se ela fosse 'neutra' e não tivesse relação com interesses sociais e políticos. (FIORENTINI, 1994, p. 48-49)

Ainda segundo o mesmo autor, na década de 70, essa visão sofrerá mudanças como resultado do desenvolvimento na realidade, dando lugar a outra abordagem que também se coloca no campo tecnicista:

O Tecnicismo-pragmático procura reduzir a matemática a um conjunto de técnicas, regras e algoritmos sem grande preocupação em fundamentá-los ou justificá-los. Na verdade, 
esse tecnicismo mecanicista procurará enfatizar o fazer em detrimento do compreender, refletir e/ou analisar. [...] Os conteúdos tendem a ser encarados como informações, regras, macetes ou princípios organizados logicamente [...] (FIORENTINI, 1994, p.48-49, grifos nossos)

Dessas afirmações não decorre a ideia de uma concepção única de educação durante as duas décadas citadas. Não. É sabido que no âmbito do ensino conviviam várias tendências e correntes com concepções de educação diferenciadas, inclusive tendências construtivistas, da educação popular e sociocultural. No entanto, pode-se afirmar ter sido "predominante" uma visão de educação transmissiva, na lógica do tecnicismo-pragmático, voltada para a aquisição de habilidades.

Isso também volta a ser colocado nos estudos de Fiorentini (1994), que analisou cerca de oitenta dissertações e teses do País, mostrando que a produção existente está sob forte influência "do ideário da pedagogia tecnicista", considerado pelo autor como sendo uma visão realmente "hegemônica no Brasil". O autor destaca, então: "[...] Os resultados desses estudos mostram que o ensino de matemática é conservador e tradicional. Metodologicamente os professores limitam-se a transmitir expositivamente os conteúdos sem discutir objetivos, estratégias de ensino e avaliação." (FIORENTINI, 1994, p. 122-123)

Saviani (1995) apresenta uma definição de ensino tradicional, como "[...] aquele que é ministrado numa instituição - a escola - de acordo com o seguinte esquema: O educador, repositório da cultura, transmite conteúdos ao educando que os capta e assimila." (p. 26). A denominação mais expressiva para esse tipo de ensino, a "educação bancária", foi criada por Paulo Freire (1983, p. 66), como "educação dissertadora", onde "em lugar de comunicar-se, o educador faz 'comunicados' e depósitos que os educandos, meras incidências, recebem pacientemente, memorizam, repetem".

Na ótica do educando, a escola tradicional, regida pelo esquema da educação bancária, a aprendizagem pode se tornar um processo muito "duro", muitas vezes incompreensível e sem significado para o aluno. Santomé (1998, p. 63) ressalta que o "problema das escolas tradicionais, nas quais se dá uma forte ênfase aos conteúdos apresentados em pacotes 
disciplinares, é que não conseguem que os alunos e alunas sejam capazes de ver esses conteúdos como parte de seu próprio mundo [...]".

Podemos, então, considerar o ensino de Matemática no Brasil predominante nas décadas de setenta e oitenta como um ensino tecnicista, pautado na lógica transmissiva de conteúdos e habilidades disciplinares previamente definidos, e nele incluída (com lugar de destaque) a disciplina Matemática. Assim, podemos considerar ser essa a principal referência ou mesmo "herança" aos docentes que querem ser bons professores de Matemática. Podemos ainda situar que a escolarização brasileira, no mesmo período, esteve marcada por uma profunda seletividade, convivendo-se com uma estrutura piramidal na qual, por razões internas à Educação e razões sociais marcantes de nossa sociedade, contingentes de crianças e jovens ficavam submetidos a reprovações sucessivas e à evasão. Logo, acreditamos poder fazer uma relação entre uma visão formal da Matemática e uma perspectiva bancária de ensino como predominante na formação e nas práticas docentes.

\section{As visões do conhecimento matemático e as relações na sala de aula}

Para que pudéssemos ampliar o nosso entendimento sobre essa forma tradicional de ensinar, remetemo-nos a Kuhn (2001, apud SOARES, 2009) cujo trabalho sugere uma articulação entre premissas e práticas que fundamentaria a adoção do modo tradicional de ensinar Ciências e Matemática. Ele toma como premissa a crença no pressuposto de um paradigma definido e que é socialmente valorizado e, também, na capacidade dos sujeitos assimilarem um conhecimento estabelecido conforme uma hierarquização por graus de dificuldade, tendo em vista a concepção proposta por um currículo escolar. Kuhn (2001) coloca que essas premissas se conjugam com a necessidade de preparar os alunos de forma mais rápida para compreender o padrão e a linguagem do referido paradigma.

Soares (2009, p. 172) traz os estudos que investigam processos de aprendizagem e que alertam para a necessidade de dialogar com os alunos e seus contextos, pois, do contrário, "corre-se o risco de 
se promover um ensino pouco ou nada significativo para eles". O autor refere-se aos estudos de Boaler (2000, apud SOARES, 2009, p. 172) "para quem a aprendizagem é uma experiência formadora de identidade, uma vez que colabora na constituição do que somos e de nossas possibilidades no mundo". Segundo Soares (2009), essa autora coloca que o distanciamento entre o que se ensina e o que realmente faz sentido para os alunos produz um sentimento de impotência em relação ao conhecimento matemático, o qual é visto como esotérico e reservado para poucos, os quais são tidos como privilegiados.

Nesse contexto, é grande a probabilidade de ocorrer dificuldade de aprendizado por parte dos alunos que não compreendem para que serve o conhecimento matemático que estão lhes transmitindo, isto é, falta sentido, falta significado com relação a esse conhecimento. Ainda que se possa destacar uma "suposta" vantagem numa visão mais formal da Matemática, no sentido de que ela já se encontra na sua forma "pronta", acreditamos que possui a desvantagem de atingir a poucos e frustrar crianças e jovens. Essa trama toda gera um dissabor para o aluno e também uma frustração no docente. Essa linha de ensino e educação tende a desenvolver uma prática pedagógica muita tensa e que, infelizmente, tem marcado o ensino de Matemática.

Quando o processo formativo se refere a uma concepção do conhecimento matemático na ótica do ensino, do ponto de vista da educação matemática, esta tende a lidar com uma lógica de contextualização dos conteúdos, de interação, de procurar saber os conhecimentos formais e sociais que os alunos possuem para que possam ser vinculados, de incorporar a visão do processo de aprendizagem onde o erro é considerado parte, de relacionar conteúdos matemáticos com conteúdos de outras disciplinas, de considerar caminhos diferenciados de pensamento, de quebrar a lógica do encadeamento e dos pré-requisitos, entre muitas outras possibilidades.

Nesse sentido, há que se ter uma flexibilização do conhecimento matemático que se desdobra, diversifica-se, aplica-se, desorganizase e relaciona-se para levar o aluno a compreender. Nessa linha, o professor pode lançar mão de diversas metodologias e abordagens, 
como, por exemplo, Modelagem Matemática ${ }^{7}$, Resolução de Problemas (POLYA, 1987), História da Matemática (MIGUEL; MIORIN, 2005), História da Educação Matemática (VALENTE, 2007), Investigação Matemática (PONTE; BROCADO; OLIVEIRA, 2003), Etnomatemática (D'AMBROSIO, 1998), dentre outras, que poderão trazer mais elementos para otimizar a prática pedagógica no dia a dia da sala de aula.

Com relação ao Laseb e outras propostas de formação continuada, observa-se que tais flexibilizações com múltiplas metodologias e possibilidades de ensino se fazem presentes, talvez até com mais liberdade por serem cursos especiais em momentos menos "controlados" pelo sistema de formação.

Ao trilhar pelo caminho dessa concepção, "do conhecimento matemático do ponto de vista da Educação Matemática", supõem-se, então, uma flexibilização dos aspectos mais formais da área, ajudando o docente a compreender melhor o seu aluno e o contexto de trabalho, o que pode gerar menos tensões na sala de aula. O professor tem mais consciência do conhecimento matemático a ser ensinado como parte da formação dos seus alunos e, nesse sentido, dá importância às relações e se coloca numa postura mais ativa, o que pode estar indicando até mesmo melhores possibilidades de ampliar as aprendizagens de seus alunos. Seria, então, esta a mudança vivida pelos professores egressos, quando citaram a mudança de relação com os seus alunos como a principal decorrência do Laseb como Curso de Especialização em formação continuada?

É bem provável que numa abordagem do conhecimento matemático de modo mais flexível (na linguagem, no uso de recursos, na articulação em situações-problema, no uso de tecnologias, como já citado) o professor possa ter mais mobilidade para criar abordagens e se planejar, identificando qual aluno tem maiores chances de um melhor aprendizado, porque este poderá ver mais sentido, mais significado do conhecimento. Esta é uma perspectiva mais formativa, humanista e sua construção tem sido uma demanda da escola que vem se universalizando, o que vem sendo uma referência central do campo da educação matemática.

7 Modelagem Matemática - no campo da Educação Matemática a Modelagem Matemática pode ser definida ou compreendida de diferentes formas. Consultar: Bassanezi (2004), Biembengut e Hein (2003), Barbosa (2004), Araújo (2002). 
No que concerne às possíveis dificuldades dessa concepção, estão as questões ligadas à necessidade de sistematização/formalização do conhecimento escolar, pois corre-se o risco de um conhecimento fragmentado e muito distante da organização matemática formal. Ou seja, tais movimentos do ensino de Matemática requerem uma ação docente voltada para um trabalho de sistematização, escolhendo como e qual o melhor momento de fazê-lo, para que as novas abordagens desenvolvidas não se configurem em um conhecimento que o próprio aluno não identifique com a Matemática ou numa simples "arejada" na lógica tradicional de ensino. Construir uma sistematização e, com os anos de escolarização, trabalhar em prol da consolidação dos conceitos ensinados e aprendidos numa organização formal matemática, é necessário para que o aluno identifique seus conhecimentos com os conhecimentos matemáticos e possa operar corretamente nesse campo científico.

Logo, tal estudo nos indica que o contato do docente da educação básica com as abordagens e visões do campo da educação matemática favorecem sobremaneira sua atuação, especialmente porque oferece instrumentos e elementos teóricos, da própria Matemática e da Pedagogia, para que atue como educador matemático. Desse modo, a experiência do curso de especialização, como formação em serviço, que proporcionou vivência de professores dos anos iniciais e finais do Ensino Fundamental e enfocou os conceitos essenciais da Matemática numa lógica de ensino, pode realmente ter criado as condições para uma mudança na relação professor-aluno, como afirmam os docentes entrevistados. Essa mudança no sentido mais interativo e dialogal na sala de aula, indicada ao docente pela necessidade de flexibilizar o conhecimento matemático e, principalmente, buscar relações do que deve ser ensinado com o que já é sabido, mostra-se potente para melhores aprendizagens e mais satisfações nos processos de ensino.

Tais inferências e indicações que aqui apresentamos, abrem caminhos para novas perguntas que podem ser feitas, necessárias para avançar na formação a partir do ensino de Matemática, tais como: quais sistematizações são essenciais para que os conceitos matemáticos sejam realmente entendidos e identificados pelos alunos? Como tratar 
o conhecimento matemático em turmas muito heterogêneas? Quais elementos, em cada uma das abordagens, podem potencializar a aprendizagem? Que formações em serviço podem acompanhar e apoiar o professor nesse novo caminho que se apresenta? São questões para novos estudos. 


\section{Referências}

ARAÚJO, J. L. Cálculo, tecnologias e modelagem matemática: as discussões dos alunos. 2002. 220 f. Tese (Doutorado em Educação Matemática) - Instituto de Geociências e Ciências Exatas, Universidade Estadual Paulista, Rio Claro, 2002.

BARBOSA, J. C. Modelagem Matemática: O que é? Por quê? Como? Veritati, n. 4, p. 73-80, 2004.

BARTH, B-M. O saber em construção: para uma teoria da compreensão. Lisboa, Portugal: Instituto Piaget, 1993. (Coleção Horizonte Pedagógicos).

BASSANEZI, R. C. Ensino-aprendizagem com modelagem matemática. São Paulo: Contexto, 2004.

BIEMBENGUT, M. S; HEIN, N. Modelagem matemática no ensino. 3. ed. São Paulo: Contexto, 2003.

BRASIL. Lei n ${ }^{0}$ 9.394, de 20 de dezembro de 1996. Estabelece as Diretrizes e Bases da Educação Nacional. Diário Oficial da União, Brasília, DF, 23 dez. 1996.

BRASIL. Ministério da Educação. Portaria n ${ }^{\circ} 1.403$, de 09 de junho de 2003. Institui o Sistema Nacional de Certificação e Formação Continuada de Professores. Diário Oficial da União, Brasília, DF, 10 jun. 2003.

CALDEIRA, A. M. S.; ZAIDAN, S. Prática pedagógica. In: OLIVEIRA, D. A.; DUARTE, A. M. C.; VIEIRA, L. M. F. (Orgs.). Dicionário:

trabalho, profissão e condição docente. Belo Horizonte, GESTRADO/ FaE/UFMG, 2010. Disponível em: <http://goo.gl/rBYOVm>. Acesso em: 22 ago. 2011. 
CARDOSO, S. de L. Possíveis repercussões na prática pedagógica que os professores egressos atribuem à especialização em Educação Matemática Laseb. 2013. 140 f. Dissertação (Mestrado em Educação) - Faculdade de Educação, Universidade Federal de Minas Gerais, Belo Horizonte, 2013.

DAVID, M. M. S. Um novo público está nos obrigando a redefinir a posição da Matemática no currículo e a repensar a prática do professor. Actas ProfMat, Lisboa, 2001.

D’AMBROSIO, B. S. Como ensinar matemática hoje? Temas e Debates, Brasília, ano 2, n. 2, p. 15-19, 1989.

D'AMBROSIO, U. Educação matemática: uma visão do estado da arte. Pró-posições, v.4, n.1, p. 7-17, 1993.

D’AMBROSIO, U. Etnomatemática. 5. ed. São Paulo: Ática, 1998.

D’AMBROSIO, U. A história da Matemática questões historiográficas e políticas e reflexos na Educação Matemática. In: BICUDO, M. A. V. (Org.). Pesquisa em Educação Matemática: concepções e perspectivas. São Paulo: Editora UNESP, 1999. p. 97-115.

FERREIRA, A. B. H. Novo dicionário Aurélio da língua portuguesa. 2. ed. Rio de Janeiro: Nova Fronteira, 1986.

FREIRE, P. Pedagogia do oprimido. Rio de Janeiro: Paz e Terra, 1983.

FIORENTINI, D. Rumos da Pesquisa Brasileira em Educação Matemática: o caso da produção científica em cursos de pós-graduação. 1994. 414 f. Tese (Doutorado em Educação) - Programa de Pós-Graduação em Educação, Universidade Estadual de Campinas, 1994.

LORENZATO, S. Por que não ensinar geometria? A Educação 
Matemática em Revista, Florianópolis, v. 4, p. 3-13, 1995.

MARCELO GARCIA, C. Desenvolvimento profissional: passado e futuro. Sísifo. Revista das Ciências da Educação, n. 8, p. 7-22, jan./abr. 2009. Disponível em: <http://goo.gl/MBG2fy>. Acesso em: 25 mar. 2012.

MARIN, A. J. Educação continuada: introdução a uma análise de termos e concepções. Cadernos Cedes - Educação Continuada, Campinas, n. 36, p. 13-20, 1995.

MIGUEL, A.; MIORIM, M. A. História na educação matemática: propostas e desafios. Belo Horizonte: Autêntica, 2005.

MOREIRA, P. C.; DAVID, M. M. M. S. A formação matemática do professor: licenciatura e prática docente escolar. Belo Horizonte: Autêntica Editora, 2007.

PAVANELLO, R. M. O abandono do ensino da geometria no Brasil: causas e consequências. Revista Zetetiké, ano 1, n. 1, 1993.

PLACCO, V. M. N. de S. Formação em serviço. In: OLIVEIRA, D. A.; DUARTE, A. M. C.; VIEIRA, L. M. F. (Orgs.). Dicionário: trabalho, profissão e condição docente. Belo Horizonte, GESTRADO/FaE/ UFMG, 2010. Disponível em: <http://goo.gl/rBYOVm>. Acesso em: 11 abr. 2012.

POLYA, G. A arte de resolver problemas. Tradução e adaptação de Heitor Lisboa de Araújo. Rio de janeiro: Interciências, 1987.

PONTE, J. P.; BROCADO, J.; OLIVEIRA, H. Investigações matemáticas na sala de aula. Belo Horizonte: Autêntica, 2003.

SANTOMÉ, J. T. Globalização e interdisciplinariedade: o currículo 
integrado. Tradução de Cláudia Schilling. Porto Alegre: Artes Médicas, 1998.

SAVIANI, D. A filosofia da educação e o problema da inovação em educação. In: WALTER, E. G. (Org.). Inovação educacional no Brasil, problemas e perspectivas. 3. ed. Campinas: Autores Associados, 1995. p. 15-29. (Coleção Educação contemporânea).

SCHÖN, D. Formar professores como profissionais reflexivos. In: NÓVOA, A. (Org.). Os professores e sua formação. Lisboa: Dom Quixote, 1992. p. 77-92.

SOARES, E. S. Reprodução e produção das condições sociais em aulas de matemática: uma perspectiva trilhada na sala de aula. 2009. 187 f. Tese (Doutorado em Educação) - Faculdade de Educação, Universidade Federal de Minas Gerais, Belo Horizonte, 2009.

VALENTE, W. R. História da Educação Matemática: interrogações metodológicas. Revemat: Revista Eletrônica de Educação Matemática, v. 2, p. 28-49, 2007.

Recebido em 20/09/2014 Aprovado em 10/11/2014 